ISSN = 1980-993X - doi:10.4136/1980-993X
www.agro.unitau.br/ambi-agua
E-mail: ambi-agua@agro.unitau.br
Tel.: (12) 3625-4116

\title{
Crescimento e conteúdo de nutrientes do cajueiro anão irrigado com águas salinas \\ (doi:10.4136/ambi-agua.111)
}

\author{
Arlington Ricardo de Oliveira ${ }^{1}$; Paulo Torre Carneiro ${ }^{2}$; Hugo Orlando Carvallo \\ Guerra $^{3}$; Pedro Dantas Fernandes ${ }^{3}$ \\ ${ }^{1}$ UFCG/CTRN/UAEAg \\ E-mail: ricardo75jp@hotmail.com \\ ${ }^{2}$ PDCR FAPEAL/UFAL \\ E-mail: ptcarneiro@yahoo.com.br \\ ${ }^{3}$ UFCG/CTRN/UAEAg \\ E-mail: hugo_carvallo@hotmail.com; pdantas@pesquisador.cnpq.br
}

\section{RESUMO}

O cultivo do caju é uma das atividades agrícolas de maior importância socioeconômica para o Nordeste brasileiro, pois, além de empregar grande contingente de pessoas, participa de forma expressiva na geração de divisas. Por outro lado, o uso inadequado da irrigação em áreas semiáridas, do Nordeste brasileiro, tem ocasionado salinização de solos e consequentes problemas para a agricultura irrigada. Apesar disto, poucos trabalhos de pesquisa têm sido realizados envolvendo o efeito do estresse salino sobre o crescimento e desenvolvimento do cajueiro. Diante da carência de resultados de pesquisa nesses aspectos, objetivou-se neste trabalho determinar a produção de fitomassa e a acumulação de nutrientes nos órgãos do cajueiro anão-precoce Clone CCP76, irrigado com águas salinas. O ensaio foi conduzido sob ambiente controlado e delineado em blocos ao acaso, com cinco níveis de salinidade da água de irrigação (Condutividades Elétricas de 0,8, 1,6, 2,4, 3,2 e 4,0 dS m ${ }^{-1}$ a $25^{\circ} \mathrm{C}$ ). O aumento da salinidade da água inibiu a produção de fitomassa do cajueiro. As concentrações de Nitrogênio, Fósforo, Potássio, Cloreto e Sódio na planta variaram com a salinidade da água de irrigação de acordo com o órgão da planta estudado. Em alguns casos, quando a salinidade da água de irrigação aumentou, a concentração do nutriente aumentou, em outros diminuiu, em outros se observou inicialmente um decréscimo para diminuir posteriormente e finalmente em outros a salinidade da água de irrigação não afetou em nada a concentração do nutriente.

Palavras-chave: caju; salinidade; fitomassa.

\section{Dwarf cashew growth irrigated with saline waters}

\section{ABSTRACT}

The cashew production is one of the most important agricultural activities from the social-economical viewpoint for the North East of Brazil; besides to produce a great deal of hand labor, it is very important as an exporting commodity. The inadequate use of irrigation in the semi arid regions of the North East of Brazil has induced soil salinization and consequently problems for the irrigated agriculture. In spite of this, few works have been conducted to study the effect of saline stress on the growth and development of the cashew. Because of the lack of information for this crop, an experiment was conducted to study the effect of salinity stress on the phytomass production and nutrient accumulation on the different organs of the precocious dwarf cashew (Anacardium occidentale L.) clone CCP76. The study was conducted under controlled conditions using as statistical scheme a randomized block design factorial with six replicates. Five salinity treatments were 
OLIVEIRA, A. R.; CARNEIRO, P. T.; GUERRA, H. O. C.; FERNANDES, P. D. Crescimento e conteúdo de nutrientes do cajueiro anão irrigado com águas salinas. Ambi-Agua, Taubaté, v. 4, n. 3, p. 181-195, 2009. (doi:10.4136/ambi-agua.111)

considered for the irrigation water (electrical conductivities of $0.8,1.6,2.4,3.2$ and $4.0 \mathrm{dS} \mathrm{m}^{-1}$ at $25^{\circ} \mathrm{C}$ ). The increasing in salinity of the irrigation water reduced the phytomass at different organs of the studied plant. The nitrogen, phosphorus, potassium, chloride and sodium in the plant varied with the salinity of the irrigation water according with the part of the plant analyzed; in some parts increased, in others decreased, in others increased initially and decreased afterwards, and finally, in other part of the plant the salinity of the irrigation water did not affect the nutrient concentration.

Keywords: Anacardium occidentale; salinity; plant mass.

\section{INTRODUÇÃO}

O cultivo do caju é uma das atividades de maior importância econômica e social para o Nordeste brasileiro, pois, além de empregar grande contingente de pessoas, participa de forma expressiva na geração de divisas externas. O Brasil tem uma área de produção de aproximadamente 710 mil ha, sendo concentrada nos Estados do Ceará (maior produtor nacional), Piauí e Rio Grande do Norte, responsáveis por cerca de 90 \% de toda produção nacional, segundo dados do IBGE (2006). Após a obtenção de clones de cajueiro anão precoce, cresceram as perspectivas de utilização da irrigação para aumento da produtividade, ampliação do período de colheita e melhoria da qualidade da castanha e do pedúnculo. Vale a pena lembrar, entretanto, que o uso inadequado da irrigação em áreas semi-áridas, predominantes no Nordeste brasileiro, tem ocasionado salinização de solos (Audry \& Suassuna, 1995) e consequentes problemas para a agricultura irrigada em diversas partes do mundo. Segundo Richards (1954), embora a principal fonte de todos os sais encontrados no solo seja a intemperização das rochas, raros são os exemplos onde essa fonte tenha provocado, diretamente, problemas de salinidade do solo. No Nordeste do Brasil, apesar da relevância socioeconômica da cajucultura e da susceptibilidade de ocorrência dos problemas de salinidade na região, poucos trabalhos de pesquisa têm sido realizados com essa cultura envolvendo estresse salino (Meireles, 1999; Ferreira et al., 2000; Bezerra, 2001; Carneiro et al., 2004), todos eles restringindo-se os efeitos da salinidade na formação de porta-enxertos e na produção de mudas enxertadas. Diante da carência de resultados de pesquisa com estresse salino em cajueiro, sobretudo a partir de mudas enxertadas, objetivou-se, neste trabalho determinar a produção de fitomassa e a acumulação do teor de nutrientes nos órgãos no cajueiro anão-precoce Clone CCP76, irrigado com águas salinas.

\section{MATERIAL E MÉTODOS}

O experimento foi conduzido em ambiente protegido do Centro de Tecnologia e Recursos Naturais (CTRN), da Universidade Federal de Campina Grande (UFCG), Campus I,

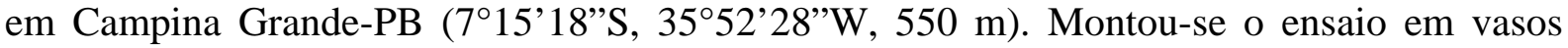
plásticos com capacidade para $170 \mathrm{l}$, perfurados na base para permitir lixiviação. Os vasos foram preenchidos com um material de solo 'franco arenoso', não salino e não sódico após seco ao ar e passado em peneira de $2 \mathrm{~mm}$ de malha. Amostras foram conduzidas ao Laboratório de Irrigação e Salinidade da UFCG em Campina Grande- PB para caracterização físico-hídrica e química. Em cada órgão da planta, determinaram-se os teores de nitrogênio, fósforo, potássio cloreto e sódio.

O nitrogênio orgânico foi determinado pelo método de Nessler (Jackson, 1965), após submeter o material vegetal à oxidação por digestão sulfúrica. O fósforo colorimetricamente pelo método do molibdato, o potássio e o sódio, por espectrofotometria de emissão de chama e digestão sulfúrica. $\mathrm{O}$ cloreto através de titulação com $\mathrm{AgNO}_{3}$. 
OLIVEIRA, A. R.; CARNEIRO, P. T.; GUERRA, H. O. C.; FERNANDES, P. D. Crescimento e conteúdo de nutrientes do cajueiro anão irrigado com águas salinas. Ambi-Agua, Taubaté, v. 4, n. 3, p. 181-195, 2009. (doi:10.4136/ambi-agua.111)

Utilizou-se o clone do enxerto CCP76 e o porta-enxerto o clone CCP06, fornecido pela Embrapa Agroindústria Tropical, produzido sem estresse salino no Campo Experimental localizado em Pacajus-CE, sendo um dos genótipos mais utilizados nos novos plantios pela qualidade das castanhas e do pedúnculo. Os tratamentos consistiram de cinco níveis de salinidade, denominados S1, S2, S3, S4 e S5, correspondendo, respectivamente, às condutividades elétricas da água de irrigação (CEa) de 0,$8 ; 1,6 ; 2,4 ; 3,2$ e $4,0 \mathrm{dS} \mathrm{m}{ }^{-1}$, à $25^{\circ} \mathrm{C}$. As águas foram preparadas mediante adição de $\mathrm{NaCl}$ comercial (sem iodo) em água da Companhia de Água e Esgoto da Paraíba (CAGEPA) - abastecimento local. Por exemplo, a planta identificada com sendo $\mathrm{S}_{3} \mathrm{BP}_{1}$, sofreu estresse salino de $2,4 \mathrm{dS} \mathrm{m}^{-1}\left(\mathrm{~S}_{3}\right)$ unicamente na fase de floração (Fase B) recebendo nas outras duas fases (A e C) irrigação com água de boa qualidade. $\mathrm{O}$ ensaio foi conduzido em blocos ao acaso, com cinco tratamentos e três repetições, constituindo-se a parcela de duas plantas. As irrigações, por gotejamento, foram efetuadas a cada três dias no início da manhã, com base no consumo de água das plantas na irrigação anterior. O delineamento experimental utilizado foi em blocos casualizados, com seis repetições, analisado em esquema fatorial $(4 \times 3)+1$, totalizando 13 tratamentos e 78 parcelas. As amostras de cada parte da planta estudada: raízes, porta-enxerto, enxerto, ramos e frutos foram colocadas em estufa a $60^{\circ} \mathrm{C}$ permanecendo nessa condição até atingir peso constante, sendo, posteriormente, pesados. Por ser a salinidade um fator de natureza quantitativa, realizou-se análise de regressão polinomial. O modelo estatístico utilizado foi o SISVAR (Sistema de Análises de Variância para dados balanceados).

\section{RESULTADOS E DISCUSSÃO}

A Tabela 1 mostra um resumo da análise de variância e médias para a fitomassa das diversas partes da plantas na frutificação, do clone CCP76 de cajueiro anão precoce, irrigadas com águas de diferentes concentrações de sais, após 90 dias de estresse salino. Os dados da Tabela 1 mostram que houve um efeito altamente significativo $(p<0,01)$ da salinidade da água de irrigação sobre a fitomassa de todas as partes da planta, observando-se um decréscimo da matéria seca com o aumento da salinidade da água de irrigação utilizada, a queda mais acentuada na planta foi observada nas folhas. Nestas foi obtido um peso médio de 490,12 g para as plantas irrigadas com o nível mais baixo de salinidade ou testemunha absoluta $\left(0,8 \mathrm{dS} \mathrm{m}^{-1}\right)$ diminuindo para 127,28 g, naquelas irrigadas com o nível mais elevado de salinidade $\left(4,0 \mathrm{dS} \mathrm{m}^{-1}\right)$.

A queda menos acentuada na fitomassa da planta foi observada nos enxertos, em que estes tiveram um peso médio de 99,13 g nas plantas irrigadas com o nível mais baixo de salinidade $\left(0,8 \mathrm{dS} \mathrm{m}^{-1}\right)$ e de 74,68g para aquelas irrigadas com o nível mais elevado de salinidade $\left(4,0 \mathrm{dS} \mathrm{m}^{-1}\right)$. As análises das regressões, também apresentadas na Tabela 1 , permitem constatar que com exceção da fitomassa dos ramos, a fitomassa das outras partes da planta (raízes, porta-enxerto, enxertos e folhas) teve uma diminuição linear. 
OLIVEIRA, A. R.; CARNEIRO, P. T.; GUERRA, H. O. C.; FERNANDES, P. D. Crescimento e conteúdo de nutrientes do cajueiro anão irrigado com águas salinas. Ambi-Agua, Taubaté, v. 4, n. 3, p. 181-195, 2009. (doi:10.4136/ambi-agua.111)

Tabela 1. Resumo da análise de variância e médias para a fitomassa nas raízes, porta-enxerto, enxerto, ramos e folhas do clone CCP76 de cajueiro anão precoce irrigado com águas de diferentes concentrações de sais, após 90 dias de estresse salino.

\begin{tabular}{|c|c|c|c|c|c|c|}
\hline \multirow{2}{*}{$\begin{array}{l}\text { Fonte de } \\
\text { Variação }\end{array}$} & \multirow{2}{*}{ GL } & Raízes & Porta-enxerto & Enxerto & Ramos & Folhas \\
\hline & & \multicolumn{5}{|c|}{ Quadrados Médios } \\
\hline Salinidade & 4 & $9919,36 * *$ & $787,58 * *$ & $503,14^{* *}$ & $124147,48 * *$ & $159397,14 * *$ \\
\hline Reg. Linear & 1 & $35932,48^{* *}$ & $2957,60 * *$ & $1867,46 * *$ & $327196,86 * *$ & $549741,02 * *$ \\
\hline Reg. Quadrática & 1 & $2668,79 n s$ & $178,08 \mathrm{~ns}$ & $71,25 * *$ & $84344,84^{* *}$ & $10773,70^{* *}$ \\
\hline Desvio & 2 & 538.08ns & 7,33ns & $36,93 * *$ & $42524,12^{* *}$ & $38536.91^{* *}$ \\
\hline Bloco & 5 & $797,54 \mathrm{~ns}$ & $160,79 \mathrm{~ns}$ & 3,79ns & $10140,35 n s$ & $671,54 \mathrm{~ns}$ \\
\hline Resíduo & 20 & 778,74 & 77,42 & 3,45 & 6700,16 & 497,19 \\
\hline \multicolumn{2}{|l|}{ CV (\%) } & 10,39 & 11,72 & 2,09 & 17,29 & 6,48 \\
\hline & & \multicolumn{5}{|c|}{ Médias } \\
\hline \multicolumn{2}{|c|}{ Condutividade Elétrica } & $\mathbf{g}$ & g & $\mathrm{g}$ & g & g \\
\hline \multicolumn{2}{|l|}{$\mathrm{S}_{1}\left(0,8 \mathrm{dS} \mathrm{m}^{-1}\right)$} & 330,05 & 86,70 & 99,13 & 723,25 & 490,12 \\
\hline \multicolumn{2}{|l|}{$\mathrm{S}_{2}\left(1,6 \mathrm{dS} \mathrm{m}^{-1}\right)$} & 281,54 & 82,30 & 93,66 & 421,22 & 523,47 \\
\hline \multicolumn{2}{|l|}{$\mathrm{S}_{3}\left(2,4 \mathrm{dS} \mathrm{m}^{-1}\right)$} & 266,83 & 78,67 & 90,04 & 460,82 & 288,97 \\
\hline \multirow{2}{*}{\multicolumn{2}{|c|}{$\begin{array}{l}S_{4}\left(3,2 d S m^{-1}\right) \\
S_{5}\left(4,0 d S m^{-1}\right)\end{array}$}} & 231,45 & 69,80 & 86,78 & 394,63 & 291,94 \\
\hline & & 232,74 & 57,84 & 74,68 & 367,31 & 127,28 \\
\hline
\end{tabular}

* e ** significativo a 5 e $1 \%$ de probabilidade, respectivamente; ${ }^{\text {ns }}$ não significativo.

Na produção de fitomassa da raiz (Figura 1A), houve redução linear ( $p<0,01)$, com decréscimo, relativo à $S_{1}$, de $7,59 \%$ por aumento unitário de CEa com relação a níveis superiores de salinidade nos demais níveis subsequentes. $\mathrm{O}$ aumento dos níveis de salinidade causou provavelmente um efeito osmótico, fazendo com que tenha havido uma redução da quantidade de fitomassa. Nos porta-enxertos, houve um decréscimo linear na fitomassa, de 7,75\% (Figura 1B). Para o enxerto (Figura 1C) de 6,97\% e para as folhas (Figura 1E) de 22\% para os níveis de salinidade superiores, relativos ao mais baixo $\left(0,8 \mathrm{dS} \mathrm{m}^{1}\right)$. Nos ramos (Figura 1D), o efeito da salinidade sobre a fitomassa, foi quadrática ( $\mathrm{p}<0,01)$, com o ponto máximo de decréscimo em $3,33 \mathrm{dS} \mathrm{m}^{-1}$ o que correspondeu a $410,66 \mathrm{gg}^{-1}$ dos ramos extraídos. A acentuada queda da fitomassa nas folhas, pode ser explicada pela senescência, em que as plantas perdem boa parte da sua copa como mecanismo de defesa. 
OLIVEIRA, A. R.; CARNEIRO, P. T.; GUERRA, H. O. C.; FERNANDES, P. D. Crescimento e conteúdo de nutrientes do cajueiro anão irrigado com águas salinas. Ambi-Agua, Taubaté, v. 4, n. 3, p. 181-195, 2009. (doi:10.4136/ambi-agua.111)
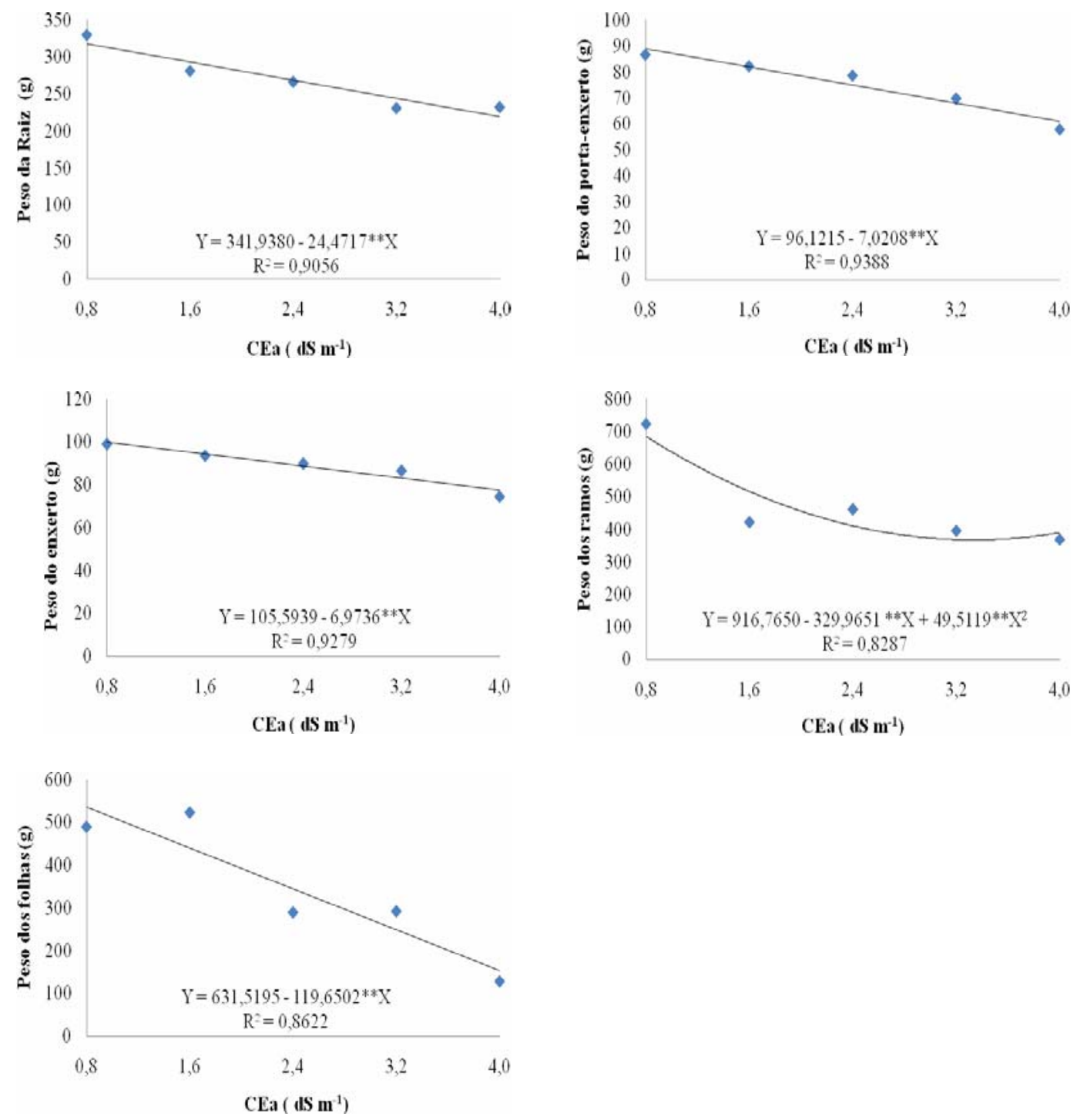

Figura 1. Fitomassa das raízes: (A), dos porta-enxertos (B), enxertos (C), ramos (D) e folhas (E) em planta do cajueiro anão-precoce, clone CCP76, função da condutividade elétrica da água (CEa) utilizada na irrigação, após 90 dias de estresse salino na frutificação.

A Tabela 2 apresenta o resumo da análise de variância e médias para o teor de nitrogênio. Com exceção das folhas em todas as outras partes da planta do caju, o efeito da salinidade da água de irrigação sobre o teor de nitrogênio teve um efeito altamente significativo $(p<0,01)$. Nas folhas o efeito foi significativo unicamente a $5 \%$ de probabilidade.

As regressões para a variação do teor de nitrogênio nas diferentes partes da planta com o aumento da salinidade e suas respectivas equações encontram-se acima na Figura 2. 
OLIVEIRA, A. R.; CARNEIRO, P. T.; GUERRA, H. O. C.; FERNANDES, P. D. Crescimento e conteúdo de nutrientes do cajueiro anão irrigado com águas salinas. Ambi-Agua, Taubaté, v. 4, n. 3, p. 181-195, 2009. (doi:10.4136/ambi-agua.111)

Tabela 2. Resumo da análise de variância e médias para o teor de nitrogênio nas raízes, portaenxerto, enxerto, ramos e folhas do clone CCP76 de cajueiro anão precoce irrigado com águas de diferentes concentrações de sais, após 90 dias de estresse salino.

\begin{tabular}{|c|c|c|c|c|c|c|}
\hline \multirow{2}{*}{ Fontes de Variação } & \multirow{2}{*}{ GL } & Raízes & Porta-enxerto & Enxerto & Ramos & Folhas \\
\hline & & \multicolumn{5}{|c|}{$\begin{array}{l}\text { Valores de Quadrados Médios } \\
\end{array}$} \\
\hline Salinidade & 4 & $2,22 * *$ & $0,53 * *$ & $1,51^{* *}$ & $0,25^{* *}$ & $0,116^{*}$ \\
\hline Reg. Linear & 1 & $5,08 * *$ & $0,42 *$ & $3,50 * *$ & $0,38 * *$ & $0,005 \mathrm{~ns}$ \\
\hline Reg. Quadrática & 1 & $2,29 * *$ & $1,54 * *$ & $1,41^{*}$ & $0,28 * *$ & $0,414 * *$ \\
\hline Desvio & 2 & $0,76^{*}$ & $0,09 \mathrm{~ns}$ & $0,56 n s$ & $0,19 * *$ & 0,023ns \\
\hline Bloco & 5 & $0,15 n s$ & $0,03 n s$ & $0,04 n s$ & $0,02 \mathrm{~ns}$ & $0,023 \mathrm{~ns}$ \\
\hline Resíduo & 20 & 0,14 & 0,07 & 0,19 & 0,02 & 0,03 \\
\hline \multicolumn{2}{|l|}{ CV (\%) } & 8,83 & 7,94 & 10,24 & 3,80 & 3,93 \\
\hline & & \multicolumn{5}{|c|}{ Médias } \\
\hline \multicolumn{2}{|c|}{ Condutividade Elétrica } & $\mathrm{g} \mathrm{kg}^{-1}$ & $\mathrm{~g} \mathrm{~kg}^{-1}$ & $\mathrm{~g} \mathrm{~kg}^{-1}$ & $\mathrm{~g} \mathrm{~kg}^{-1}$ & $\mathrm{~g} \mathrm{~kg}^{-1}$ \\
\hline \multicolumn{2}{|c|}{$\mathrm{S}_{1}\left(0,8 \mathrm{dS} \mathrm{m}^{-1}\right)$} & 9,09 & 13,60 & 10,84 & 13,60 & 15,58 \\
\hline \multicolumn{2}{|l|}{$\mathrm{S}_{2}\left(1,6 \mathrm{dS} \mathrm{m}^{-1}\right)$} & 19,22 & 11,41 & 19,22 & 14,44 & 17,94 \\
\hline \multicolumn{2}{|l|}{$\mathrm{S}_{3}\left(2,4 \mathrm{dS} \mathrm{m}^{-1}\right)$} & 17,38 & 8,56 & 17,38 & 15,31 & 18,10 \\
\hline \multicolumn{2}{|l|}{$\mathrm{S}_{4}\left(3,2 \mathrm{dS} \mathrm{m}^{-1}\right)$} & 21,35 & 9,16 & 21,35 & 11,76 & 16,81 \\
\hline \multicolumn{2}{|l|}{$\mathrm{S}_{5}\left(4,0 \mathrm{dS} \mathrm{m}^{-1}\right)$} & 19,64 & 11,92 & 19,64 & 12,02 & 15,76 \\
\hline
\end{tabular}

* e ** significativo a 5 e $1 \%$ de probabilidade, respectivamente; ${ }^{\text {ns }}$ não significativo.
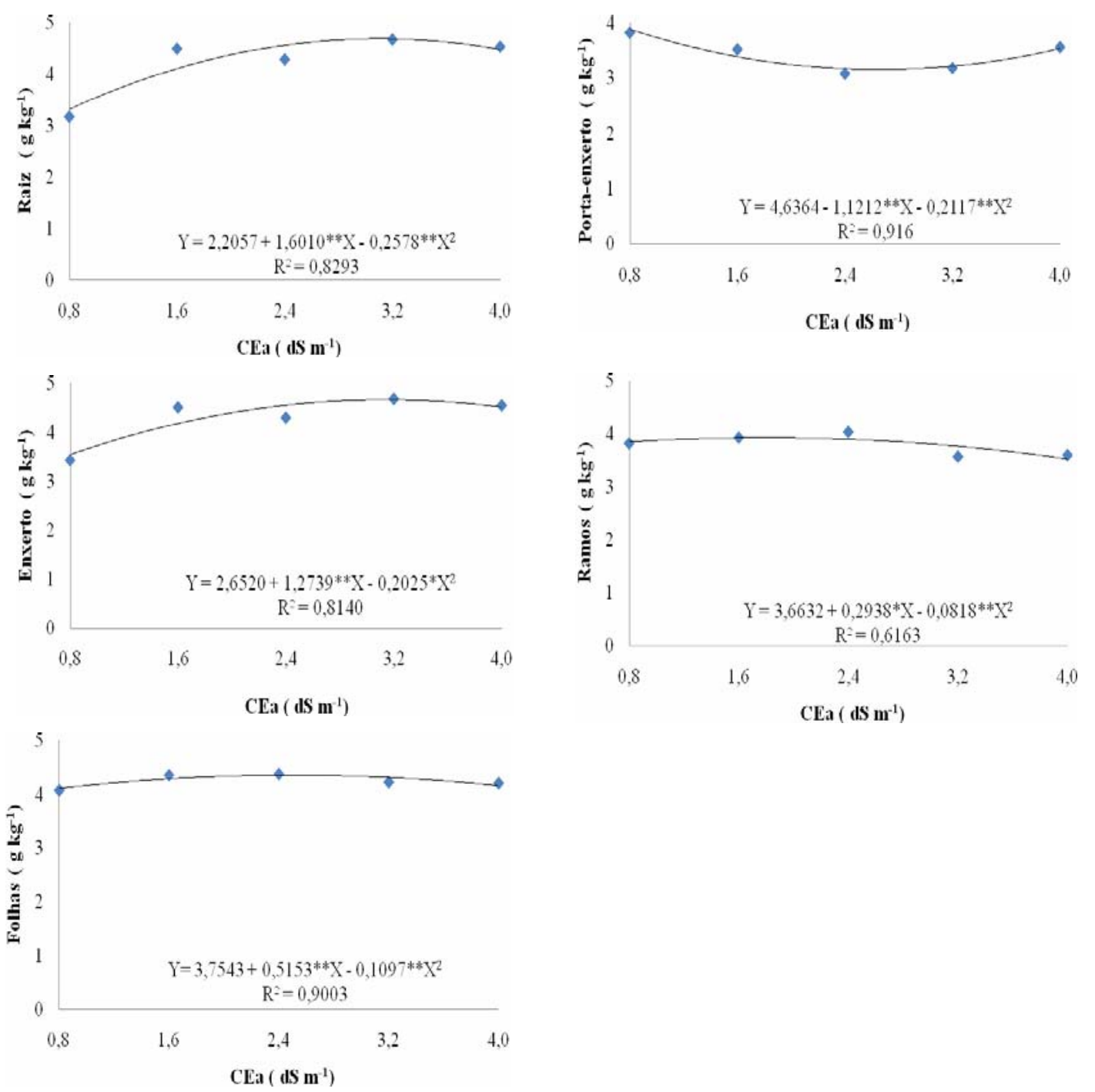

Figura 2. Teor de nitrogênio das raízes (A), dos porta-enxertos (B), dos enxertos (C), dos ramos (D) e folhas (E) em planta do cajueiro anão-precoce, clone CCP76. 
OLIVEIRA, A. R.; CARNEIRO, P. T.; GUERRA, H. O. C.; FERNANDES, P. D. Crescimento e conteúdo de nutrientes do cajueiro anão irrigado com águas salinas. Ambi-Agua, Taubaté, v. 4, n. 3, p. 181-195, 2009. (doi:10.4136/ambi-agua.111)

O efeito da salinidade sobre o teor de nitrogênio teve um efeito quadrático $(\mathrm{p}<0,01)$ para todas as partes da planta do cajueiro anão precoce. Tanto na raiz (Figura 2A) como no enxerto (Figura 2C) os comportamentos foram semelhantes e se verificou um incremento no teor de $\mathrm{N}$ de acordo com o aumento da condutividade elétrica da água utilizada para irrigação, com ponto de máximo em 3,11 $\mathrm{dS} \mathrm{m}^{-1}$ no caso da raiz e de $2,15 \mathrm{dS} \mathrm{m}^{-1}$ para o enxerto.

Após os máximos, houve uma diminuição do teor de $\mathrm{N}$ com o aumento da salinidade da água de irrigação. No caso do porta-enxerto (Figura 2B), observou-se um decréscimo da concentração do $\mathrm{N}$ tendo seu ponto mínimo em 2,65 dS $\mathrm{m}^{-1}$ e, em seguida, observa-se um aumento do teor ao tempo que há aumento dos níveis de salinidade da água. Nos ramos (Figura 2D) e folhas (Figura 2E), os pontos máximos foram de 1,80 e 2,35 dS m m $^{-1}$, respectivamente.

A Tabela 3 apresenta o resumo da análise de variância e as médias para o teor de fósforo O efeito da salinidade da água de irrigação sobre o teor de fósforo teve um efeito altamente significativo $(\mathrm{p}<0,01)$ para os enxertos, ramos e folhas.

Tabela 3. Resumo da análise de variância e médias para o teor de fósforo nas raízes, porta-enxerto, enxerto, ramos e folhas do clone CCP76 de cajueiro anão precoce irrigado com águas de diferentes concentrações de sais, após 90 dias de estresse salino.

\begin{tabular}{|c|c|c|c|c|c|c|}
\hline \multirow{2}{*}{ Fontes de Variação } & \multirow{2}{*}{ GL } & Raízes & Porta-enxertos & Enxertos & Ramos & Folhas \\
\hline & & \multicolumn{5}{|c|}{ Quadrados Médios } \\
\hline Salinidade & 4 & $0,13 n s$ & 0,0889ns & $0,26 * *$ & $0,133^{* *}$ & $0,024 * *$ \\
\hline Reg. Linear & 1 & $0,002 \mathrm{~ns}$ & $0,0010 \mathrm{~ns}$ & $0,90 * *$ & $0,095 * *$ & $0,027^{*}$ \\
\hline Reg. Quadrática & 1 & $0,004 \mathrm{~ns}$ & $0,3458 n s$ & 0,11 ns & $0,045^{*}$ & $0,045^{* *}$ \\
\hline Desvio Regressão & 2 & $0,259 \mathrm{~ns}$ & $0,0043 n s$ & $0,02 \mathrm{~ns}$ & $0,196 * *$ & $0,010 \mathrm{~ns}$ \\
\hline Bloco & 5 & $0,02 \mathrm{~ns}$ & $0,047 \mathrm{~ns}$ & $0,05 n s$ & $0,010 \mathrm{~ns}$ & $0,023^{* *}$ \\
\hline Resíduo & 20 & 0,05 & 0,11 & 0,03 & 0,008 & 0,004 \\
\hline \multicolumn{2}{|l|}{ CV (\%) } & 10,75 & 15,03 & 7,80 & 3,89 & 4,11 \\
\hline & & \multicolumn{5}{|c|}{ Médias } \\
\hline \multicolumn{2}{|c|}{ Condutividade Elétrica } & $\mathrm{g} \mathrm{kg}^{-1}$ & $\mathrm{~g} \mathrm{~kg}^{-1}$ & $\mathrm{~g} \mathrm{~kg}^{-1}$ & $\mathrm{~g} \mathrm{~kg}^{-1}$ & $\mathrm{~g} \mathrm{~kg}^{-1}$ \\
\hline \multicolumn{2}{|c|}{$\mathrm{S}_{1}\left(0,8 \mathrm{dS} \mathrm{m}^{-1}\right)$} & 2,93 & 3,10 & 2,16 & 4,70 & 1,45 \\
\hline \multicolumn{2}{|l|}{$\mathrm{S}_{2}\left(1,6 \mathrm{dS} \mathrm{m}^{-1}\right)$} & 3,72 & 3,42 & 3,12 & 5,07 & 1,13 \\
\hline \multicolumn{2}{|l|}{$\mathrm{S}_{3}\left(2,4 \mathrm{dS} \mathrm{m}^{-1}\right)$} & 3,50 & 3,61 & 3,95 & 3,34 & 1,37 \\
\hline \multicolumn{2}{|l|}{$\mathrm{S}_{4}\left(3,2 \mathrm{dS} \mathrm{m}^{-1}\right)$} & 2,35 & 4,31 & 3,90 & 4,57 & 1,37 \\
\hline \multicolumn{2}{|l|}{$\mathrm{S}_{5}\left(4,0 \mathrm{dS} \mathrm{m}^{-1}\right)$} & 3,73 & 4,60 & 4,31 & 4,08 & 1,68 \\
\hline
\end{tabular}

* e ** significativo a 5 e $1 \%$ de probabilidade, respectivamente; ${ }^{\text {ns }}$ não significativo

As análises de regressão para a variação do teor de fósforo nas diferentes partes da planta com o aumento da salinidade da água de irrigação e suas respectivas equações encontram-se na Figura 3. O efeito da salinidade sobre o teor de P no enxerto e nos ramos (Figura 3A e 3B) foi linear ( $\mathrm{p}<0,01)$, e houve um incremento de 9,96\% do teor de fósforo no enxerto por

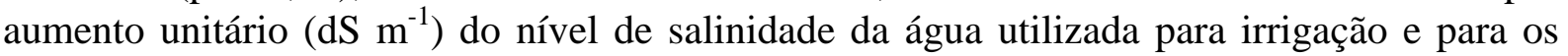
ramos um decréscimo de 1,66\%. Já para as folhas (Figura 3C), o efeito da salinidade foi quadrático ( $\mathrm{p}<0,01)$, com um decréscimo máximo nos níveis de salinidade de 2,03 dS m $\mathrm{m}^{-1}$. Stauffer e Sulewski (2004) sugerem que devido ao fato de o P ser tão fortemente ligado aos processos metabólicos da planta, ele é móvel nos tecidos da planta e fica concentrado nas áreas mais ativas de crescimento e onde também ocorre a redistribuição do $\mathrm{P}$ de um lugar de residência para outro qualquer, tal como folhas velhas para as folhas ou brotos novos ou do lenho para os ramos novos as flores ou os frutos. Os mesmos autores sugerem ainda que sob condições limitantes de $\mathrm{P}$, as plantas normalmente apresentam pequeno desenvolvimento de raízes e de brotações e, como resultado, ocorre exploração insuficiente do solo, resultando em acesso restrito e baixa eficiência de uso, tanto de água quanto de nutrientes. Sendo assim, 
OLIVEIRA, A. R.; CARNEIRO, P. T.; GUERRA, H. O. C.; FERNANDES, P. D. Crescimento e conteúdo de nutrientes do cajueiro anão irrigado com águas salinas. Ambi-Agua, Taubaté, v. 4, n. 3, p. 181-195, 2009. (doi:10.4136/ambi-agua.111)

isso indica que, tendo em vista que as folhas mais velhas são afetadas antes das mais novas, pela fase fisiológica que a planta se encontrava, poderia acontecer um equilíbrio nutricional dentro da planta, independentemente da salinidade da água utilizada na irrigação.
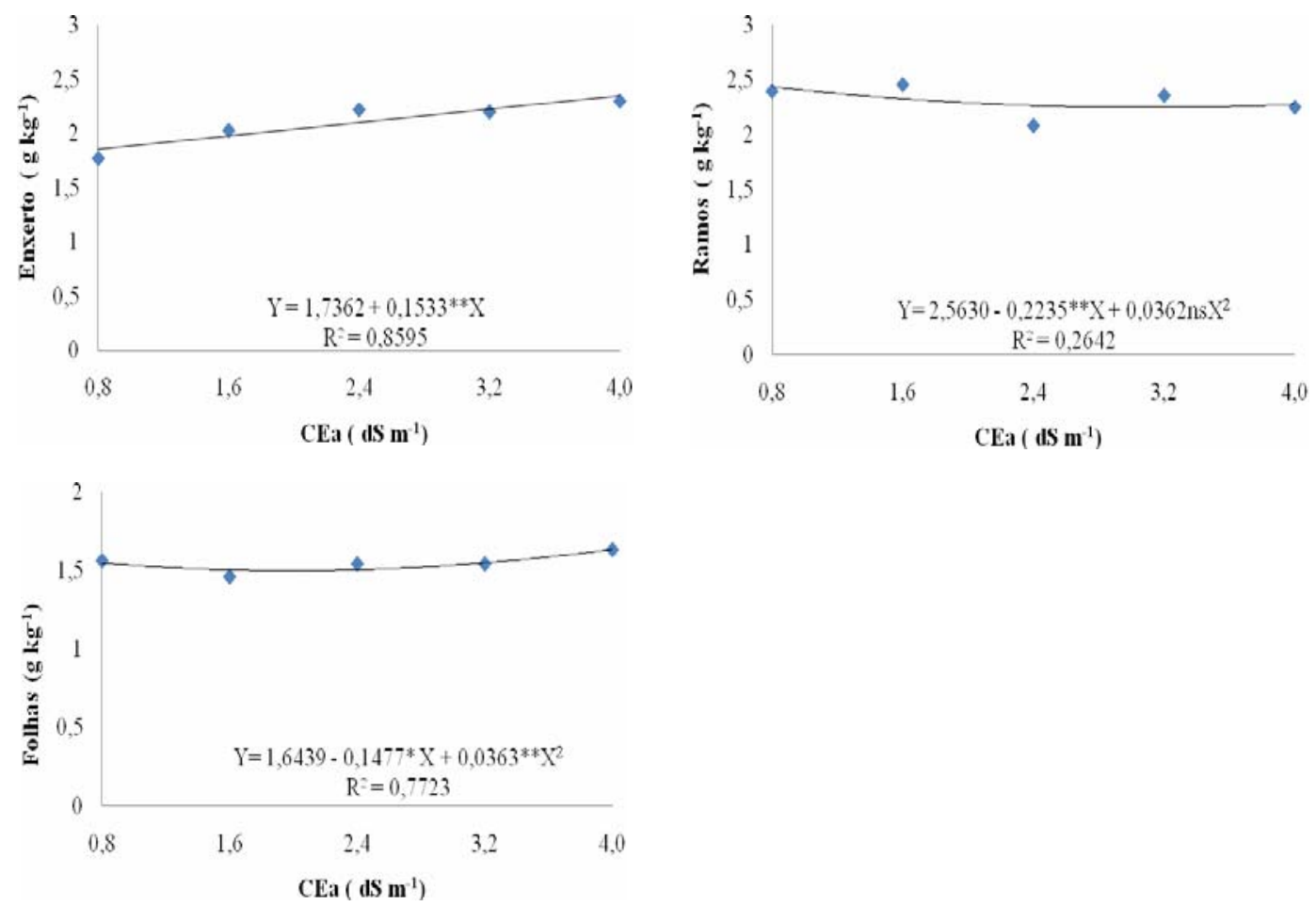

Figura 3. Teor de nutrientes dos enxertos (A), dos ramos (B) e folhas (C) em planta do cajueiro anão-precoce, clone CCP76, função da condutividade elétrica da água (CEa) utilizada na irrigação, após 90 dias de estresse salino na frutificação.

Observa-se na Tabela 4 que o efeito da salinidade da água de irrigação sobre o teor de potássio teve um efeito significativo ao $1 \%$ de probabilidade $(\mathrm{p}<0,01)$ para os portaenxertos, ramos e folhas e não significância para as raízes e enxertos; em geral houve um decréscimo do teor de potássio com a salinidade da água de irrigação. Kawasaki et al., (1983) indicam que o aumento da concentração de sódio do meio externo ocasiona a diminuição dos teores de potássio nos tecidos das plantas, pois o aumento da concentração de sódio no meio radicular inibe a absorção de potássio devido à relação competitiva entre estes cátions monovalentes.

As folhas são a parte das plantas onde se observa a maior queda com relação à

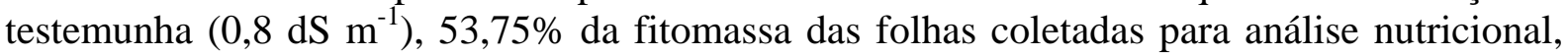
em seguida vêm os ramos com uma queda de 39,95\%. A menor variação desses teores na planta foi registrada nos porta-enxertos, onde o teor de potássio nas plantas irrigadas com $\mathrm{CE}_{\mathrm{a}}$ de $0,8 \mathrm{dS} \mathrm{m}^{-1}$ e as irrigadas com 4,0 dS m $\mathrm{m}^{-1}$, decresceu um 6,30\%. 
OLIVEIRA, A. R.; CARNEIRO, P. T.; GUERRA, H. O. C.; FERNANDES, P. D. Crescimento e conteúdo de nutrientes do cajueiro anão irrigado com águas salinas. Ambi-Agua, Taubaté, v. 4, n. 3, p. 181-195, 2009. (doi:10.4136/ambi-agua.111)

Tabela 4. Resumo da análise de variância e médias para o teor de potássio nas raízes, porta-enxerto, enxerto, ramos e folhas do clone CCP76 de cajueiro anão precoce irrigadas com águas de diferentes concentrações de sais, após 90 dias de estresse salino.

\begin{tabular}{|c|c|c|c|c|c|c|}
\hline \multirow{2}{*}{ Fontes de Variação } & \multirow{2}{*}{ GL } & Raízes & Porta-enxertos & Enxertos & Ramos & Folhas \\
\hline & & \multicolumn{5}{|c|}{ Valores de Quadrados Médios } \\
\hline Salinidade & 4 & $0,06 \mathrm{~ns}$ & $0,18 * *$ & $0,03 \mathrm{~ns}$ & $0,65^{* *}$ & $1,26 * *$ \\
\hline Reg. Linear & 1 & $0,15 n s$ & $0,16^{* *}$ & 3,50ns & $1,25^{* *}$ & $1,24 * *$ \\
\hline Reg. Quadrática & 1 & $0,04 \mathrm{~ns}$ & $0,24^{* *}$ & $1,41 \mathrm{~ns}$ & $0,84^{* *}$ & $3,15^{* *}$ \\
\hline Desvio Regressão & 2 & $0,03 n s$ & $0,16 * *$ & $0,56 \mathrm{~ns}$ & $0,25 * *$ & $0,32 \mathrm{~ns}$ \\
\hline Bloco & 5 & 0,03 ns & $0,04 \mathrm{~ns}$ & $0,02 \mathrm{~ns}$ & $0,07 \mathrm{~ns}$ & $0,11 \mathrm{~ns}$ \\
\hline Resíduo & 20 & 0,06 & 0,02 & 0,01 & 0,02 & 0,09 \\
\hline \multirow[t]{2}{*}{ CV (\%) } & & 11,13 & 5,80 & 6,38 & 6,28 & 14,36 \\
\hline & & \multicolumn{5}{|c|}{ Médias } \\
\hline \multicolumn{2}{|l|}{ Condutividade Elétrica } & $\mathrm{g} \mathrm{kg}^{-1}$ & $\mathrm{~g} \mathrm{~kg}^{-1}$ & $\mathrm{~g} \mathrm{~kg}^{-1}$ & $\mathrm{~g} \mathrm{~kg}^{-1}$ & $\mathrm{~g} \mathrm{~kg}^{-1}$ \\
\hline \multicolumn{2}{|l|}{$\mathrm{S}_{1}\left(0,8 \mathrm{dS} \mathrm{m}^{-1}\right)$} & 4,19 & 4,60 & 2,56 & 7,66 & 7,46 \\
\hline \multicolumn{2}{|l|}{$\mathrm{S}_{2}\left(1,6 \mathrm{dS} \mathrm{m}^{-1}\right)$} & 4,30 & 3,42 & 2,56 & 6,24 & 2,15 \\
\hline \multicolumn{2}{|l|}{$\mathrm{S}_{3}\left(2,4 \mathrm{dS} \mathrm{m}^{-1}\right)$} & 4,19 & 3,10 & 2,15 & 3,32 & 2,14 \\
\hline \multicolumn{2}{|l|}{$\mathrm{S}_{4}\left(3,2 \mathrm{dS} \mathrm{m}^{-1}\right)$} & 3,37 & 3,61 & 2,76 & 4,60 & 2,50 \\
\hline \multicolumn{2}{|l|}{$\mathrm{S}_{5}\left(4,0 \mathrm{dS} \mathrm{m}^{-1}\right)$} & 3,37 & 4,31 & 2,15 & 4,60 & 3,45 \\
\hline
\end{tabular}

* e ** significativo a 5 e $1 \%$ de probabilidade, respectivamente; ns : não significativo.

As análises de regressão para a variação do teor de potássio nas diferentes partes da planta com o aumento da salinidade da água de irrigação e suas respectivas equações encontram-se na Figura 4.
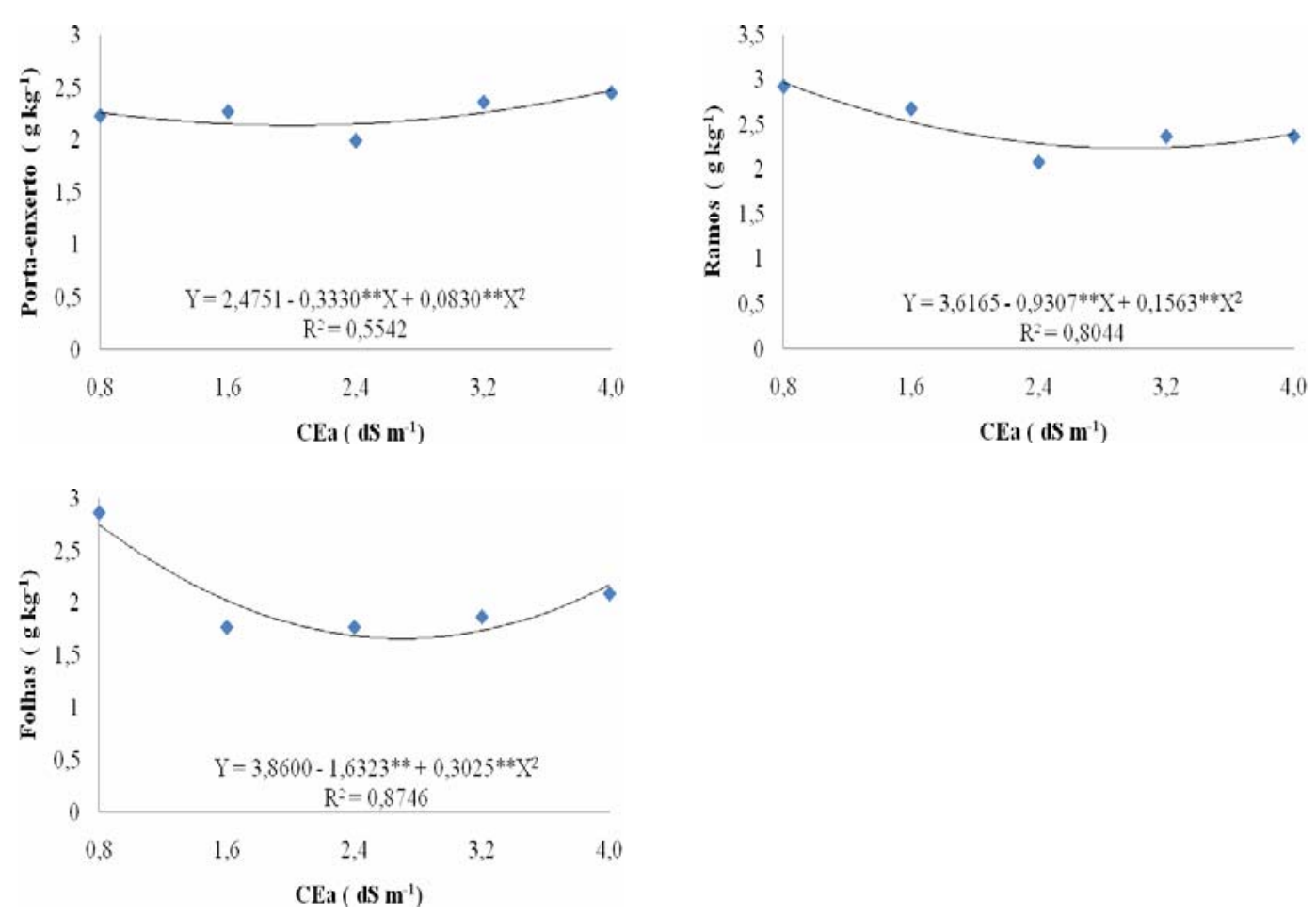

Figura 4. Teor de potássio nos porta-enxertos (A), nos ramos (B) e folhas (C) em planta do cajueiro anão-precoce, clone CCP76, função da condutividade elétrica da água (CEa) utilizada na irrigação, após 90 dias de estresse salino na frutificação.

Como antecipado na Tabela 4, o efeito da salinidade da água de irrigação sobre o teor de potássio foi quadrático ( $<0,01)$ nos porta-enxertos (Figura 4A), ramos (Figura 4B) e folhas 
OLIVEIRA, A. R.; CARNEIRO, P. T.; GUERRA, H. O. C.; FERNANDES, P. D. Crescimento e conteúdo de nutrientes do cajueiro anão irrigado com águas salinas. Ambi-Agua, Taubaté, v. 4, n. 3, p. 181-195, 2009. (doi:10.4136/ambi-agua.111)

(Figura 4C). Observa-se um aumento no acúmulo de $\mathrm{K}$, no caso do porta-enxerto com ponto de máximo em 2,01 dS m $\mathrm{m}^{-1}$ e decréscimo para os ramos e folhas com ponto máximo de 2,98 e $2,70 \mathrm{dS} \mathrm{m}^{-1}$, respectivamente. Soares (2006) observou que não houve diferença estatística no teor de K nas folhas das cultivares de banana Prata Anã e Grand Naine irrigadas com águas de CE de 0,31 e 1,66 dS $\mathrm{m}^{-1}$, respectivamente, no entanto, observou que os teores de $\mathrm{K}$ nas folhas dessas duas cultivares com as duas águas de irrigação, começaram a decrescer aos 210 DAT ocasionado, provavelmente, pela translocação desse nutriente para o fruto, fato que acontece normalmente no final do ciclo de crescimento da planta. No cajueiro em estudo pode ter acontecido uma situação semelhante tendo em vista que a planta se encontrava também no final do ciclo (frutificação).

A Tabela 5 mostra que a salinidade da água de irrigação teve um efeito altamente significativo $(\mathrm{p}<0,01)$ sobre o teor de cloreto nos porta-enxertos, enxertos e folhas. $\mathrm{O}$ aumento do teor de $\mathrm{Cl}$ no caule da planta com o aumento da salinidade da água de irrigação deve-se principalmente ao fato de que as águas foram preparadas com cloreto de sódio, e assim, à medida que aumentava a salinidade da água aumentava a quantidade de cloreto adicionado ao solo. Para as folhas, a diferença entre o maior e o menor nível de salinidade da água de irrigação sendo que para $0,8 \mathrm{dS} \mathrm{m}^{-1}$ tiveram peso médio de $0,85 \mathrm{mg} \mathrm{kg}^{-1}$ e enquanto

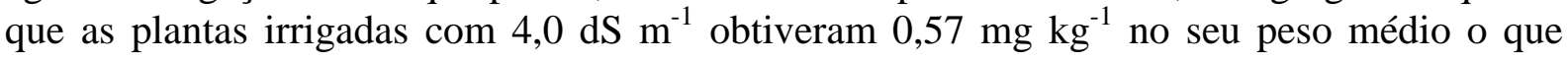
proporcionou uma decréscimo de 32,94\% no teor médio de cloreto.

O maior acréscimo do teor médio de cloreto foi verificado nos enxertos, em que as médias desses teores foram de 0,37 e $0,79 \mathrm{mg} \mathrm{kg}^{-1}$, respectivamente, para as plantas irrigadas com $\mathrm{CE}_{\mathrm{a}}$ de $0,8 \mathrm{dS} \mathrm{m}^{-1}$ e 4,0 dS m $\mathrm{m}^{-1}, 53,16 \%$ do maior para o menor nível da $\mathrm{CE}_{\mathrm{a}}$. Nas raízes e ramos obteve-se um acréscimo de 33 e $6 \%$ do maior para o menor nível da $\mathrm{CE}_{\mathrm{a}}$, respectivamente.

Tabela 5. Resumo da análise de variância e médias para o teor de cloreto nas raízes, portaenxerto, enxerto, ramos e folhas do clone CCP76 de cajueiro anão precoce irrigadas com águas de diferentes concentrações de sais, após 90 dias de estresse salino.

\begin{tabular}{|c|c|c|c|c|c|c|}
\hline \multirow{2}{*}{ Fontes de Variação } & \multirow{2}{*}{ GL } & Raízes & Porta-enxertos & Enxertos & Ramos & Folhas \\
\hline & & \multicolumn{5}{|c|}{ Valores de Quadrados Médios } \\
\hline Salinidade & 4 & $0,012 \mathrm{~ns}$ & $0,025 * *$ & $0,0307 * *$ & $0,0308 n s$ & $0,034 * *$ \\
\hline Reg. Linear & 1 & $0,036 \mathrm{~ns}$ & $0,038 * *$ & $0,0749 * *$ & $0,0048 n s$ & $0,021 \mathrm{~ns}$ \\
\hline Reg. Quadrática & 1 & $0,006 \mathrm{~ns}$ & $0,001 \mathrm{~ns}$ & $0,0167 * *$ & $0,0002 \mathrm{~ns}$ & $0,067 * *$ \\
\hline Desvio Regressão & 2 & $0,004 n s$ & $0,032 * *$ & $0,0155 * *$ & $0,0595 * *$ & $0,023 \mathrm{~ns}$ \\
\hline Bloco & 5 & $0,002 \mathrm{~ns}$ & $0,003 \mathrm{~ns}$ & $0,0008 \mathrm{~ns}$ & $0,005 \mathrm{~ns}$ & $0,005 \mathrm{~ns}$ \\
\hline Resíduo & 20 & 0,005 & 0,003 & 0,0010 & 0,0021 & 0,007 \\
\hline \multicolumn{2}{|l|}{ CV (\%) } & 5,19 & 4,42 & 2,60 & 3,52 & 6,60 \\
\hline & & \multicolumn{5}{|c|}{ Médias } \\
\hline \multicolumn{2}{|c|}{ Condutividade Elétrica } & $\mathrm{mg} \mathrm{kg}^{-1}$ & $\mathrm{mg} \mathrm{kg}^{-1}$ & \begin{tabular}{|l|} 
mg kg $^{-1}$ \\
\end{tabular} & $\mathrm{mg} \mathrm{kg}^{-1}$ & $\mathrm{mg} \mathrm{kg}^{-1}$ \\
\hline & 0,58 & 0,55 & 0,37 & 0,63 & 0,85 \\
\hline \multicolumn{2}{|l|}{$\mathrm{S}_{2}\left(1,6 \mathrm{dS} \mathrm{m}^{-1}\right)$} & 0,68 & 0,82 & 0,56 & 0,83 & 0,58 \\
\hline \multicolumn{2}{|l|}{$\mathrm{S}_{3}\left(2,4 \mathrm{dS} \mathrm{m}^{-1}\right)$} & 0,59 & 0,85 & 0,82 & 0,46 & 0,33 \\
\hline \multirow{2}{*}{\multicolumn{2}{|c|}{$\begin{array}{l}\mathrm{S}_{4}\left(3,2 \mathrm{dS} \mathrm{m}^{-1}\right) \\
\mathrm{S}_{5}\left(4,0 \mathrm{dS} \mathrm{m}^{-1}\right)\end{array}$}} & 0,74 & 0,63 & 0,62 & 0,94 & 0,64 \\
\hline & & 0,87 & 0,98 & 0,79 & 0,67 & 0,57 \\
\hline
\end{tabular}

* e ** significativo a 5 e $1 \%$ de probabilidade, respectivamente; ${ }^{\text {NS }}$ não significativo.

As análises de regressão para a variação do teor de cloreto nas diferentes partes da planta com a salinidade da água de irrigação e suas respectivas equações encontram-se na Figura 5. A variação dos teores de cloreto com a salinidade da água de irrigação nos porta enxertos e enxertos se ajustaram de uma forma altamente significativa $(\mathrm{p}<0,01)$ a uma reta (Figuras $5 \mathrm{~B}$ e 5C). Para as folhas, ajustaram-se a uma equação quadrática. Supostamente, a redução do 
OLIVEIRA, A. R.; CARNEIRO, P. T.; GUERRA, H. O. C.; FERNANDES, P. D. Crescimento e conteúdo de nutrientes do cajueiro anão irrigado com águas salinas. Ambi-Agua, Taubaté, v. 4, n. 3, p. 181-195, 2009. (doi:10.4136/ambi-agua.111)

crescimento, acompanhada pelo desenvolvimento de sintomas de toxidez de cloro, pode ser devida à redução do potencial osmótico gerado pelo $\mathrm{NaCl}$ no solo ou acúmulo de sais nos tecidos da plantas e, consequentemente, seu acúmulo no caule do cajueiro de acordo com aumento da CE da água usada na irrigação.

Os resultados encontrados no presente trabalho estão de acordo com o verificado por Yahya (1998), em que relata que o efeito osmótico tem sido a causa maior da redução do crescimento das plantas, associado à toxicidade de íons pela absorção excessiva de sódio e cloro e ao desequilíbrio nutricional causado pelos distúrbios na absorção e/ou distribuição dos nutrientes essenciais.
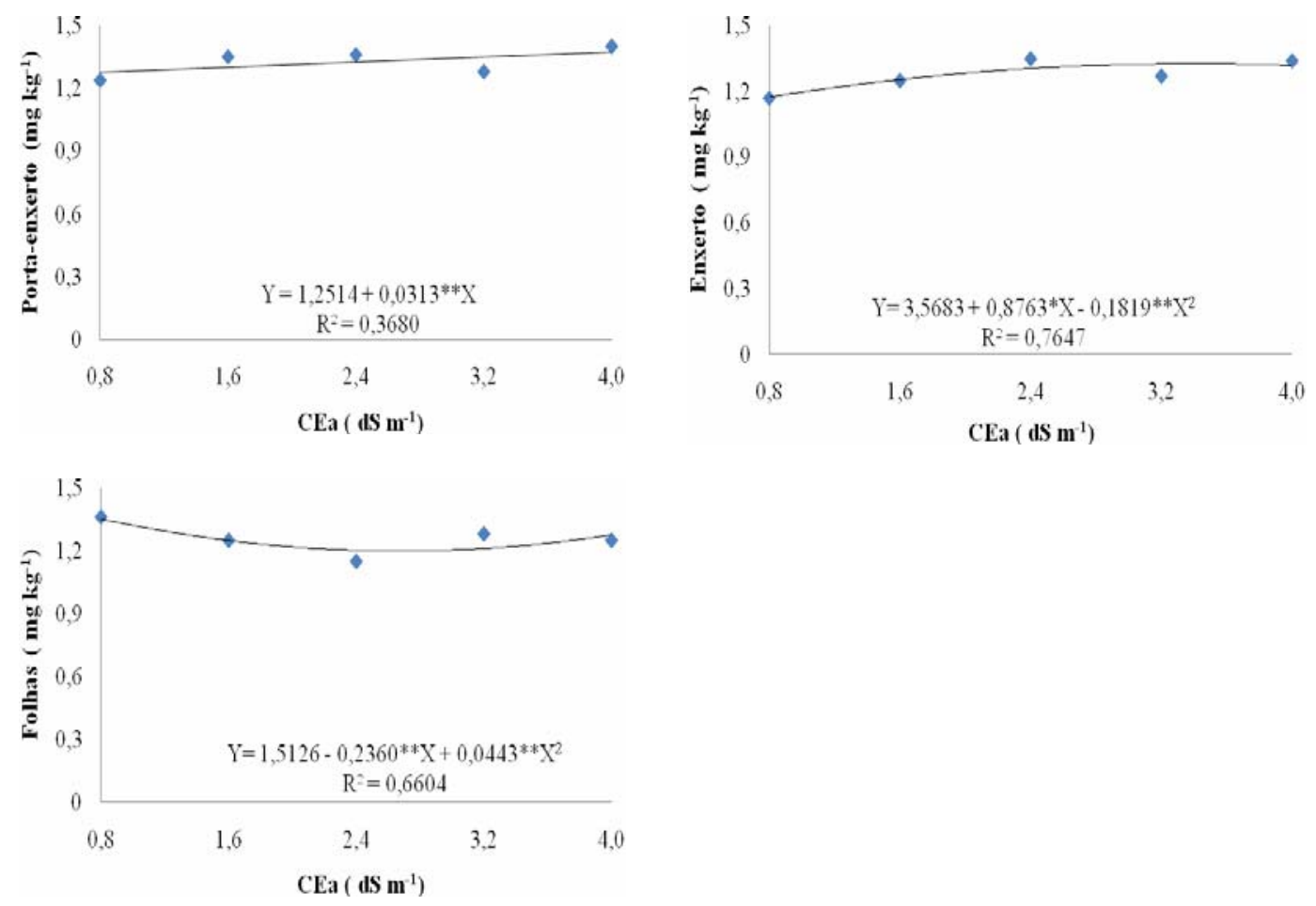

Figura 5. Teor de cloreto nos porta-enxertos (A), nos enxertos (B), e folhas (C) em planta do cajueiro anão-precoce, clone CCP76, função da condutividade elétrica da água (CEa) utilizada na irrigação, após 90 dias de estresse salino na frutificação.

A Tabela 6 apresenta um resumo da análise de variância e médias para o teor de sódio nas raízes, porta-enxerto, enxerto, ramos e folhas do clone CCP76 de cajueiro anão precoce irrigadas com águas de diferentes concentrações de sais, aos 90 dias de estresse salino na frutificação. A Tabela mostra efeito altamente significativo da salinidade da água de irrigação $(\mathrm{p}<0,01)$ sobre o teor de sódio em todas as partes da planta com exceção nas das folhas em que não foi observado efeito estatisticamente significativo. Observa-se que, com exceção das folhas, em geral houve um aumento do teor de sódio em todas as partes da planta com o aumento da salinidade da água de irrigação. Isso se deve, principalmente, ao fato de que as águas foram preparadas com cloreto de sódio, e assim, à medida que aumentava a salinidade da água, aumentava a quantidade de sódio adicionado ao solo. No caso das folhas, talvez o caju direcione o sódio para as folhas velhas (com baixa atividade metabólica, como relatado por Shannon et al. (1994) para algumas espécies tolerantes à salinidade. Segundo Marschner (1995), haveria uma restrição da importação de sódio e cloro para as folhas jovens, sendo esta uma característica de espécies tolerantes à salinidade. 
OLIVEIRA, A. R.; CARNEIRO, P. T.; GUERRA, H. O. C.; FERNANDES, P. D. Crescimento e conteúdo de nutrientes do cajueiro anão irrigado com águas salinas. Ambi-Agua, Taubaté, v. 4, n. 3, p. 181-195, 2009. (doi:10.4136/ambi-agua.111)

Tabela 6. Resumo da análise de variância e médias para o teor de sódio (Na) nas diversas partes da planta na frutificação: raízes, porta-enxerto, enxerto, ramos e folhas do clone CCP76 de cajueiro anão precoce irrigadas com águas de diferentes concentrações de sais, após 90 dias de estresse salino.

\begin{tabular}{|c|c|c|c|c|c|c|}
\hline \multirow{2}{*}{ Fontes de Variação } & \multirow{2}{*}{ GL } & Raízes & Porta-enxertos & Enxertos & Ramos & Folhas \\
\hline & & \multicolumn{5}{|c|}{ Valores de Quadrados Médios } \\
\hline Salinidade & 4 & $1,29 * *$ & $0,934 * *$ & $0,51^{* *}$ & $0,59 * *$ & $0,3725 \mathrm{~ns}$ \\
\hline Reg. Linear & 1 & $1,18^{* *}$ & $3,679 * *$ & $1,40 * *$ & $1,56 * *$ & $0,0003 n s$ \\
\hline Reg. Quadrática & 1 & $3,66 * *$ & $0,051 \mathrm{~ns}$ & $0,07 \mathrm{~ns}$ & $0,61 *$ & $1,1389 n s$ \\
\hline Desvio Regressão & 2 & $0,15 \mathrm{~ns}$ & $0,004 n s$ & $0,28 * *$ & $0,09 \mathrm{~ns}$ & $0,1753 n s$ \\
\hline Bloco & 5 & $0,03 n s$ & $0,051 \mathrm{~ns}$ & $0,10 \mathrm{~ns}$ & $0,19 \mathrm{~ns}$ & $0,0511 \mathrm{~ns}$ \\
\hline Resíduo & 20 & 0,10 & 0,157 & 0,05 & 0,11 & 0,1361 \\
\hline CV (\%) & & 12,65 & 14,46 & 8,74 & 11,86 & 8,40 \\
\hline
\end{tabular}

\begin{tabular}{|c|c|c|c|c|c|}
\hline Condutividade Elétrica & $\mathrm{mg} \mathrm{kg}^{-1}$ & $\mathrm{mg} \mathrm{kg}^{-1}$ & $\mathrm{mg} \mathrm{kg}^{-1}$ & $\mathrm{mg} \mathrm{kg}^{-1}$ & $\mathrm{mg} \mathrm{kg}^{-1}$ \\
\hline \multirow{5}{*}{$\begin{array}{l}\mathrm{S}_{1}\left(0,8 \mathrm{dS} \mathrm{m}^{-1}\right) \\
\mathrm{S}_{2}\left(1,6 \mathrm{dS} \mathrm{m}^{-1}\right) \\
\mathrm{S}_{3}\left(2,4 \mathrm{dS} \mathrm{m}^{-1}\right) \\
\mathrm{S}_{4}\left(3,2 \mathrm{dS} \mathrm{m}^{-1}\right) \\
\mathrm{S}_{5}\left(4,0 \mathrm{dS} \mathrm{m}^{-1}\right)\end{array}$} & 2,58 & 3,81 & 3,68 & 4,49 & 15,66 \\
\hline & 5,00 & 5,36 & 4,47 & 6,85 & 21,18 \\
\hline & 8,67 & 7,00 & 5,50 & 8,83 & 19,37 \\
\hline & 7,33 & 8,14 & 4,61 & 7,91 & 19,22 \\
\hline & 4,73 & 9,41 & 7,53 & 8,60 & 16,71 \\
\hline
\end{tabular}

* e ** significativo a 5 e $1 \%$ de probabilidade, respectivamente; ${ }^{\text {NS }}$ não significativo.

As análises de regressão para a variação do teor de sódio nas diferentes partes da planta com o aumento da salinidade da água de irrigação e suas respectivas equações encontram-se na Figura 6. Para o teor de Na nas raízes, ramos e folhas, houve um efeito quadrático ( $\mathrm{p}<$ 0,01) estatisticamente significativo da salinidade da água de irrigação (Figuras 6A, 6D e 6E); já para o porta-enxerto (Figura 6B) e o enxerto (Figura 6C) foi linear ( $<<0,01)$. Para as folhas, não houve diferença significativa do teor de Na com relação aos níveis da CE da água utilizada na irrigação do cajueiro anão precoce.

De acordo com a Figura 6, o efeito da salinidade da água utilizada para irrigação no teor de sódio na raiz (Figura 6A) tem seu ponto máximo em 2,76 dS m e nos ramos (figura 6D) 3,16 dS $\mathrm{m}^{-1}$. Quanto ao porta-enxerto (Figura 6B) e o enxerto (Figura 6C) houve um incremento de $13,79 \%$ e $14,14 \%$, respectivamente, por aumento unitário de salinidade da água de irrigação.

Das partes da planta que tiveram significância, com exceção das raízes, as demais partes da planta do cajueiro anão precoce tiveram um crescente aumento dos teores de sódio o que pode estar de acordo com citação de Fernandes (2000) que diz que o sódio pode agir estimulando o desenvolvimento vegetal, pois, é considerado um elemento útil para muitas culturas por efeitos fisiológicos próprios ou por substituir parte do $\mathrm{K}^{+}$requerido pela planta. 
OLIVEIRA, A. R.; CARNEIRO, P. T.; GUERRA, H. O. C.; FERNANDES, P. D. Crescimento e conteúdo de nutrientes do cajueiro anão irrigado com águas salinas. Ambi-Agua, Taubaté, v. 4, n. 3, p. 181-195, 2009.
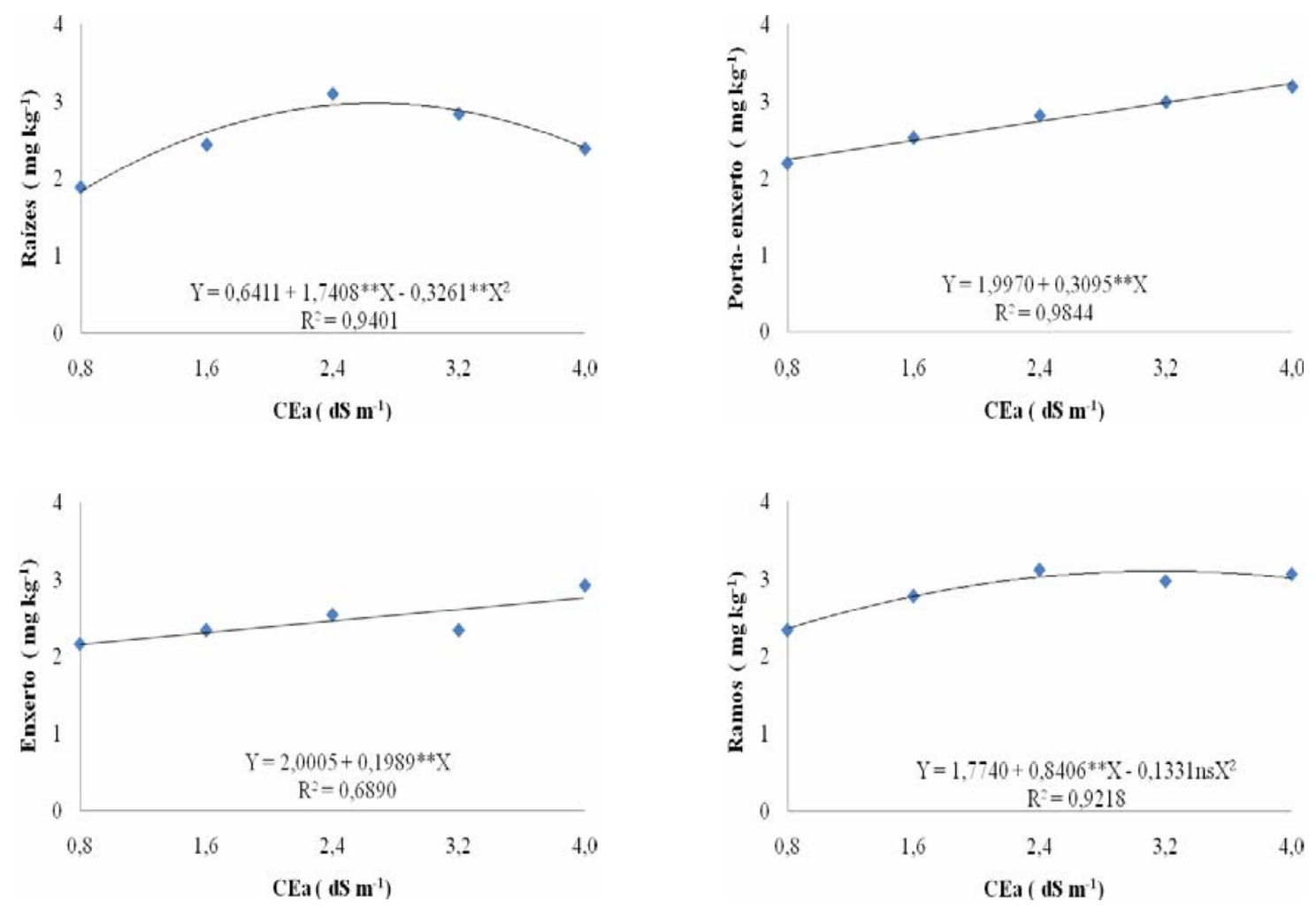

Figura 6. Teor de nutrientes das raízes (A), dos porta-enxertos (B), dos enxertos (C) e ramos (D) em planta do cajueiro anão-precoce, clone CCP76, função da condutividade elétrica da água (CEa) utilizada na irrigação, após 90 dias de estresse salino na frutificação.

O grau dessa substituição dependerá do potencial de absorção e da translocação de $\mathrm{Na}^{+}$ para a parte aérea da planta, bem como da eficiência da planta em utilizar o $\mathrm{K}^{+}$, o que é possivelmente aceito, tendo em vista que a planta se encontra na fase de frutificação, fase responsável pelo período muito grande da demanda de potássio, tendo em vista a formação dos frutos. Por exemplo, na presença de elevada concentração externa de sódio, a absorção de potássio e cálcio pode ser inibida, causando deficiência desses nutrientes e aumento no teor de sódio nas células das plantas (Subbarao apud Fernandes, 2000).

\section{CONCLUSÃO}

Com o aumento da salinidade da água de irrigação, houve um decréscimo da fitomassa em todas as partes da planta do cajueiro. A concentração de nitrogênio nas raízes, enxertos e porta-enxerto aumentou com a salinidade. Já nas folhas e ramos, o teor de nitrogênio permaneceu praticamente constante. Com exceção das folhas, os teores de cloreto e sódio aumentaram com a salinidade da água de irrigação. O enxerto foi a parte da planta onde se observou o maior aumento de fósforo com o aumento da concentração da água utilizada na irrigação. A concentração da salinidade na água de irrigação aumentou o teor de fósforo no enxerto diminuindo nos ramos. As folhas tiveram um decréscimo aumentando depois de atingir uma concentração máxima. Os porta-enxertos, ramos e as folhas diminuíram o teor de potássio com a salinidade da água de irrigação. Tanto para os porta-enxertos quanto para os enxertos, houve um acréscimo no teor de cloreto com a salinidade da água de irrigação. Já nas folhas observou-se um decréscimo. Com exceção das raízes, as demais partes da planta do cajueiro anão precoce tiveram um crescente aumento dos teores de sódio com a salinidade da água de irrigação. 


\section{REFERÊNCIAS}

AUDRY, P.; SUASSUNA, J. A salinidade das águas disponíveis para a pequena irrigação no sertão do Nordeste: caracterização, variação sazonal, limitação de uso. Recife: CNPq, 1995. 128 p.

BEZERRA, I. L. Produção de mudas enxertadas de cajueiro anão precoce, usando águas de diferentes salinidades. 2001. 85f. Dissertação (Mestrado em Engenharia Agrícola) Universidade Federal da Paraíba, Campina Grande, 2001.

CARNEIRO, P. T.; FERNANDES, P. D.; GHEYI, H. R.; SOARES, F. A. L.; VIANA, S. B. A. Salt tolerance of precocious dwarf cashew rootstocks - physiological and growth indexes. Scientia Agricola, v. 61, n. 1, p. 9-16, 2004.

BEZERRA, I. L. Produção de mudas enxertadas de cajueiro anão precoce, usando águas de diferentes salinidades. 2001. 85f. Dissertação (Mestrado em Engenharia Agrícola) Universidade Federal da Paraíba, Campina Grande, 2001.

FERNANDES, A. R. Nutrição mineral e crescimento de mudas de pupunheira (Bactris gasipaes H. B. K.), em solução nutritiva, em função do balanço de nutrientes e níveis de salinidade. Lavras, 2000. 145p.

FERREIRA, O. S.; MATOS, N. N.; MENESES JÚNIOR, J.; BARROS, L. de M.; LIMA JÚNIOR, A.; SILVEIRA, J. A. G. da. Avaliação inicial da tolerância ao estresse salino em materiais de cajueiro (Anacardium occidentale L.) através de índices de crescimento. In: CONGRESSO BRASILEIRO DE FRUTICULTURA, 16, 2000, Fortaleza. Anais... Fortaleza: SBF, 2000. 1 CD-Rom.

INSTITUTO BRASILEIRO DE GEOGRAFIA E ESTATÍSTICA. Anuário Estatístico do Brasil. Rio de Janeiro: IBGE, 2006.

JACKSON, M. L. Nitrogen determinations for soil and plant tissue. In: JACKSON, M.L. (Ed). Soil chemical analysis. Englewood Cliffs: Prentice-Hall, 1965. p. 195-196.

KAWASAKI, T.; AKIBA, T.; MORITSUGU, M. Effects of high concentrations of sodium chloride and polyethylene glycol on the growth and ion absorption in plants: I. Water culture experiments in a greenhouse. Plant and Soil, 75:75-85, 1983.

MARSCHNER, H. Mineral nutrition of higher plants. 2a ed. Londres, Academic Press, 1995, 889p.

MEIRELES, A. C. M. Salinidade da água de irrigação e desenvolvimento de mudas de cajueiro anão-precoce (Anacardium occidentale L.). 1999. 60f. Dissertação (Mestrado em Irrigação e Drenagem) - Universidade Federal do Ceará, Fortaleza, 1999.

RICHARDS, L. A. (ed.). Diagnoses and improvement of saline and alkali soils. Washington: United States Salinity Laboratory, 1954. 160 p. (USDA. Agriculture Handbook, 60).

SHANNON, M. C.; GRIEVE, C. M.; FRANCOIS, L. E. Whole-plant response to salinity. In: Plant environmental interactions. Wilkinson E. R. ed. 1994. cap. 7, p.199-244.

SISVAR. Sistema de análise de variância para dados balanceados: versão 4.3. Software para análises estatísticas por meio do Windows. Lavras: UFLA, 2003. 
OLIVEIRA, A. R.; CARNEIRO, P. T.; GUERRA, H. O. C.; FERNANDES, P. D. Crescimento e conteúdo de nutrientes do cajueiro anão irrigado com águas salinas. Ambi-Agua, Taubaté, v. 4, n. 3, p. 181-195, 2009. (doi:10.4136/ambi-agua.111)

SOARES, F. A. L. Crescimento, nutrição mineral e produção de bananeiras irrigadas com águas de salinidades diferentes. Campina Grande: Universidade Federal de Campina Grande, 2006. 171 p. (Tese de doutorado).

STAUFFER, M. D.; SULEWSKI, G. Fósforo: essencial para a vida. In: Simpósio Sobre Fósforo na Agricultura Brasileira, Piracicaba. Anais... Piracicaba: Potafos/Anda, 2004.

YAHYA, A. Salinity effects on growth and on uptake and distribution of sodium and some essential mineral nutrients in sesame. Journal of Plant Nutrition, v.21, n.7, p. 14391451, 1998. 